\title{
From Renaissance Scholars to Renaissance Communities: Learning and Education in the 21st Century
}

\author{
Gerhard Fischer \\ Center for LifeLong Learning and Design (L3D) \\ Department of Computer Science, and Institute of Cognitive Science \\ Boulder, Colorado USA \\ Gerhard@colorado.edu
}

\section{INVITED PAPER}

\begin{abstract}
The understanding, framing, and support of learning, working, communicating, and collaborating is media-dependent: tools, materials, and social arrangements have always been involved in defining and conceptualizing these activities. Historically the emphasis has been to educate and support individual "Renaissance scholars". In today's world, most of the significant problems are systemic problems that transcend not only the individual human mind but cannot be addressed by any one specialty discipline. To cope with these problems requires not only "Renaissance Scholars" but "Renaissance Communities" in which stakeholders coming from different disciplines can collaborate.
\end{abstract}

Our research at the Center for Lifelong Learning \& Design (L3D) over the past two decades has been focused on creating a new understanding of learning, new media, and new learning organizations. Our co-evolutionary perspective explores the dialectical relationship between:

- how a deep understanding of learning creates innovative demands and design criteria for future generations of social-technical environments;

- $\quad$ how the unique potential of computational media impacts and transforms learning by transcending "giftwrapping" and "technology-centered" approaches; and

- how new learning organizations contribute to reconceptualizing and reinventing learning and education in the 21 st century.

The conceptual framework is illustrated by specific developments of social-technical environments that we have designed and evaluated including: collaborative, domain-oriented design environments, environments created by mass collaboration, and courses-as-seeds.

Keywords-Renaissance Communities; meta-design; cultures of participation; social creativity; communities of interest

\section{INTRODUCTION}

The complexities of systemic problems transcend not only the individual human mind but cannot be addressed by any one specialty discipline. Based on the constraints on human abilities what we can learn during a lifetime, we cannot expect individuals to maintain the prerequisite knowledge in their technological discipline, and at the same time to have the needed competence in the social sciences and in domainspecific application domains (e.g., a computer scientist knowing about a variety of tools and at the same time understanding relevant issues in cognitive science, sociology, anthropology and having acquired substantial knowledge in specific domains). Being a "Renaissance Scholar" (such as Leonardo da Vinci, who was equally adept in the arts and the sciences [1]) was a realistic possibility in the $15^{\text {th }}$ century, the objective of learning and education in the $21^{\text {st }}$ century should be focused on "Renaissance Communities".

\section{LEARNING AND EDUCATION IN RENAISSANCE COMMUNITIES}

The power of the unaided individual mind is highly overrated. Although society often thinks of creative individuals as working in isolation, intelligence and creativity result in large part from interaction and collaboration with other individuals. Much human creativity is social, arising from activities that take place in contexts in which interaction with other people and the artifacts that embody collective knowledge are essential components. We need to invent alternative social organizations and new media that will permit the flourishing of deep interdisciplinary specialties, as argued for by Campbell [2]: "Even within disciplines, disciplinary competence is not achieved in individual minds, but as a collective achievement made possible by the overlap of narrow specialties."

Numerous sources provide overwhelming evidence that individual, disciplinary competence is limited, but the potential of a community is limitless:

- "While the Western belief in individualism romanticizes this perception of the solitary creative process, the reality is that scientific and artistic forms emerge from the joint thinking, passionate 
conversations, emotional connections, and shared struggles common in meaningful relationships" [3].

- "Nobody knows who the last Renaissance man really was, but sometime after Leonardo da Vinci, it became impossible to learn enough about all the arts and the sciences to be an expert in more than a small fraction of them" [4].

- "None of us is as smart as all of us" [5].

- "Linux was the first project to make a conscious and successful effort to use the entire world as a talent pool" [6].

Our research has been centered for many years on creating human-centered socio-technical environments empowering humans to think, work, design, learn, and collaborate in new ways. These environments have explored (1) multiple perspectives of learning [7]; (2) new and different relationships between humans and computers [8]; and (3) alternative learning organizations [9]. We have explored, designed, and evaluated innovative approaches to learning in different social infrastructures including schools, universities, work environments, homes and social networks and we have focused on individuals (being interested and knowledgeable in special domains) and different communities (including communities of practice and communities of interest). Our research has been influenced by a variety of different philosophies and visions of learning including:

- Dewey's and Bruner's [10] notion that students should be actively engaged participants in learning, sharing their knowledge with each other rather than competing to get good grades;

- Illich's Learning Webs (articulated 25 years before the Internet came into existence [11]) that represent an early vision based on two objectives: (1) provide all who want to learn with access to available resources at any time in their lives; and (2) empower all who want to share what they know to find those who want to learn it from them.

\section{A. Renaissance Communities}

Learning in "Renaissance Communities" explores rich ecologies of learning and teaching supported by information and communication technologies. It includes specific forms such as online learning and distance learning in networked and ubiquitous environments, allowing learners to access information not only in formal learning environments such as schools, but at any place where they might be [12]. To become stakeholders in "Renaissance Communities", learners should be able to interact with people of diverse backgrounds and participate in collaborative environments with ever-changing disciplinary boundaries

The following objectives should be taken into account to support "Renaissance Communities":

- $\quad$ people can pursue their own interests and goals (selfdirected learning) and they can get feedback on their understanding from computational critics and from their peers [7];
- content is personalized to a user's situation with context-aware systems [13];

- new information can be acquired and learned when it is needed (learning on demand) [14];

- $\quad$ people can learn with and about technology (thereby greatly diminishing the traditional goals of memorizing facts and learning to carry out routine operations) [15];

- $\quad$ unique opportunities of social production are exploited in which all learners can act as active contributors in personally meaningful problems $[16,17]$; and

- web-based technologies can reach more people, engage them actively (Web 2.0), and make education more affordable by using technology to refigure the economics of higher education $[17,18]$.

To achieve these objectives, the co-evolution between learning, new media, and new learning organizations (see Figure 1) is necessary.

New information and communication technologies have been heralded as the major driving forces behind innovation in learning and education. But many approaches have had only a minor impact based on the reduction to:

- technology-centered developments (sole focus on the yellow component in Figure 1): Technology alone does not determine social structure but it creates feasibility spaces for new social and cultural practice [17]. Changes in complex learning environments are not only dictated by technology; rather, they are the result of an incremental shift in human behavior and social organizations and as such require the co-design of social and technical systems.

- gift-wrapping (taken the blue component in Figure 1 as a given): Many uses of new media can be characterized as "gift-wrapping" [19]: they are used as add-ons to existing practices rather than a catalyst for fundamentally rethinking what education should and can be in the next century. They change the medium, but leave the content unchanged and contribute little to introducing new epistemologies. Existing frameworks, such as instructionism, fixed curricula, memorization, decontextualized learning and so forth, are not changed by technology itself. This is true whether we use computer-based training, intelligent tutoring systems,

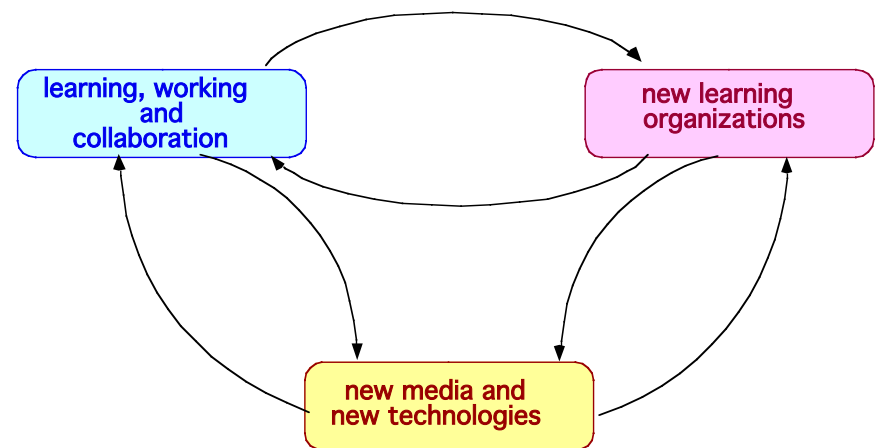

Figure 1: The co-evolution between learning, new media, and new learning organizations 
or multimedia presentations.

- $\quad$ a sole focus on existing learning organizations (not exploring new possibilities of the red component in Figure 1): e-learning environments including massive open online courses (MOOCs), peer-support communities [20] and niche communities of special, idiosyncratic interests $[21,22]$ have provided new opportunities for collaborative learning, but have often been reduced to "gift-wrapping" approaches by conceptualizing "distance learning as classroom learning at a distance".

\section{B. Innovative Multi-Dimensional Aspects of Learning}

As the demands for learning undergo a period of profound transformation, there is a need for exploring innovative multidimensional aspects of learning: people need to (1) learn more things ("what"); (2) learn in different ways than before ("how"); (3) learn everywhere instead only in formal learning environments ("where"); (4) learn throughout their lives and at times when the information is needed ("when"); and (5) learn from peers and not only from teachers ("with whom") [12].

What to Learn: Exploring Personally Meaningful Problems and Acquiring Basic Skills and Core Competencies. In formal learning environments, students' learning is determined to a large extent by a curriculum. Learners encounter few opportunities to gain experiences by exploring personally meaningful problems that need to be identified and framed. The engagement with personal meaningful problems should be complemented with learning opportunities to acquire the basic skills and core competencies for the $21^{\text {st }}$ century [15]. These competencies do not primarily consist of learning and memorizing facts, but should be focused on (1) acquiring and using information; (2) identifying, organizing, planning and allocating resources; (3) collaborating with others; and (4) working with a variety of technologies.

How to Learn: Learning in Different Ways. Learning in today's world must conceptualize learning as an inclusive, social, informal, participatory, and creative lifelong activity. Many problems (specifically design problems) are unique and ill-defined and the knowledge to address them is not "out there" requiring contributions and ideas from all involved stakeholders. Learners in such settings must be active contributors rather than passive consumers and the learning environments and organizations must foster and support mindsets, tools, and skills that help learners become empowered and willing to actively contribute [16, 23].

Where to Learn: At the Right Places. Historically, schools provided the setting where individuals engaged in learning. The seeds of a new education system can be seen in the explosive growth of home schooling, workplace learning, distance education, adult education, and a variety of design spaces (museums, zoos, environmental centers, educational television and videos, computer-based learning environments, and Internet cafes). Research on everyday cognition demonstrates that the formal learning in schools and the informal learning in practical settings have important differences [12]. What we discover about learning in schools is insufficient for a theory of human learning: schools are often focused on individual cognition, on memorization and on learning general facts whereas learning in the world at large need to rely on shared cognition, use of powerful tools and external information sources, and situation-specific competencies [24].

When to Learn: At the Right Time. Information overload and the rapid change of our world have created new problems and new challenges for learning and education. People will have to keep learning new knowledge and skills throughout their lifetimes as their lives and jobs keep changing. New approaches are needed to circumvent the unsolvable problems of coverage and obsolescence. Learning on demand [14] is a promising approach for addressing these problems because: (1) it contextualizes learning by allowing it to be integrated into work rather than relegating it to a separate phase, (2) it lets learners see for themselves the usefulness of new knowledge for actual problem situations, thereby increasing the motivation for learning new things, and (3) it makes new information relevant to the task at hand, thereby leading to more informed decision making, better products, and improved performance.

With whom: Collaborative Human-Centered Systems. As argued above, to deal with complex multi-disciplinary problems, individuals need socio-technical environments for finding, analyzing, manipulating, and communicating knowledge bringing different and often controversial points of view together in creating a shared understanding among all participating stakeholders that can lead to new insights, ideas, and artifacts. In today's world, when individuals are stuck, they can explore a vast network of information and use social networks to discuss with others their opinions on what to do and what to study.

\section{CONCEPTUAL FRAMEWORKS FOR RENAISSANCE COMMUNITIES}

Over the last two decades, we have developed conceptual frameworks to understand, support, foster, and nurture "Renaissance Communities" that emphasize the following aspects:

- meta-design defines and creates social and technical infrastructures for cultures of participation in which new forms of collaborative learning and design can arise;

- $\quad$ social creativity transcends the individual human mind by making sense of the variety of voices, in order to frame and solve systemic problems. Shared artifacts enable relevant transdisciplinary collaborations;

- cultures of participation in which all people are provided with the means to participate actively in personally meaningful problems;

- $\quad$ rich ecologies of participation are marked by different levels of participation based on different levels of expertise, interests, and motivation;

- communities of interest bring together stakeholders from different communities of practice. 


\section{A. Meta-Design}

Meta-design ("design for designers") [25] represents a theoretical framework, supported by innovative information and communication technologies, in which learners of all ages can pursue topics of interest and take responsibility for their own learning and education by empowering them to thrive and participate as co-designers in collaborative environments with ever-changing disciplinary boundaries.

Meta-design requires some fluency with information technologies and it is instrumental for the ability to reformulate knowledge, to express oneself creatively, and to create information rather than simply to comprehend it. It supports stakeholders to engage in interest-driven, selfdirected learning by supporting them in designing and building their own socio-technical environments by situating computation in new contexts and by developing tools that democratize design, innovation, and knowledge creation.

\section{B. The Seeding, Evolutionary Growth, and Reseeding (SER) Model}

The SER model [9] is a descriptive and prescriptive model for creating systems that best fit emerging and evolving contexts. Instead of attempting to build complete systems, the SER model advocates building seeds that can evolve over time. It postulates that systems that evolve over a sustained time span must continually alternate between periods of planned activity and unplanned evolution, and periods of deliberate (re)structuring and enhancement.

A seed is built based on an initial understanding and framing of a problem. It is created by meta-designers acting as environment developers for future users to be as complete as possible. However, the understanding of a problem cannot be complete due to the situated and tacit nature of knowledge work. The evolutionary growth phase is one of decentralized evolution as the seed is used and extended by users to do their work or explore new problems. In this phase, the original developers are not directly involved because the focus has shifted to the problem framing and problem solving activities of the users. Instead, the development is performed by participants who have a direct stake in the problem at hand [16]. Reseeding is a deliberate and centralized effort to organize, formalize, and generalize solutions and artifacts created during the evolutionary growth phase. The goal of reseeding is to create an information space in which useful solutions can be easily found, reused, and extended. As in the seeding phase, developers are needed to perform substantial system and solution space modifications and users must participate because only they can judge what solutions are useful and what structures will serve their work practices.

\section{Social Creativity}

Our focus on social creativity [19] is grounded in the basic observation that the power of the unaided individual mind is highly overrated. As argued before, much human creativity is social, arising from activities that take place in contexts in which interaction with other people and the artifacts that embody collective knowledge are essential components.
Social creativity does not necessitate the development of environments in which the interests of the many inevitably supersede those of the individual. Individuality makes a difference, and organizations get their strength to a large extent from the creativity and engagement of their individual members. Social creativity derives its strength from

(1) externalized shared artifacts (specifically in the form of boundary objects) which can be critiqued and incrementally improved by all stakeholders [10];

(2) conceptual collisions [26], symmetry of ignorance [27], and epistemological pluralisms [28], which allows new viewpoints and concepts to emergence thereby avoiding group-think [29]; and

(3) engaging more minds and broadening participation with the support of meta-design [25].

\section{Cultures of Participation}

The rise in social computing (based on social production and mass collaboration) [17] has facilitated a shift from consumer cultures (specialized in producing finished goods to be consumed passively) to cultures of participation (in which all people are provided with the means to participate actively in personally meaningful problems).

Cultures of participation [8] offer important and interesting possibilities to cope with major problems our societies are facing today including: (1) problems of a magnitude which individuals and even large teams cannot solve (2) problems of a systemic nature requiring the collaboration of many different minds from a variety of background; and (3) problems modeling changing and unique worlds being dependent on open, living information repositories and tools.

Cultures of participation are facilitated and supported by a variety of different technological environments (such as the participatory Web 2.0, table-top computing, domain-oriented design environments); all of them contributing in different ways to the aims of engaging diverse audiences, enhancing creativity, sharing information, and fostering the collaboration among users acting as active contributors and designers. They democratize design and innovation [16] by shifting power and control towards users, supporting them to act as both designers and consumers ("prosumers") and allowing systems to be shaped through real-time use. But being able to act as active contributors creates numerous demands for learning that need to be supported by powerful learning environments.

\section{E. Rich Ecologies of Participation}

Individuals have different motivations for doing things, and those motivations create different levels of participation. To understand, foster, and support cultures of participation requires differentiating, analyzing, and supporting distinct roles that can be found in cultures of participation [30]. Figure 2 illustrates different roles in Open Source Software communities that we have identified in one of our studies [31]. Participants start as passive users and a certain percentage of these do migrate over time to more demanding roles. Not every participant must contribute, but all participants must have opportunities to contribute when they want to. 


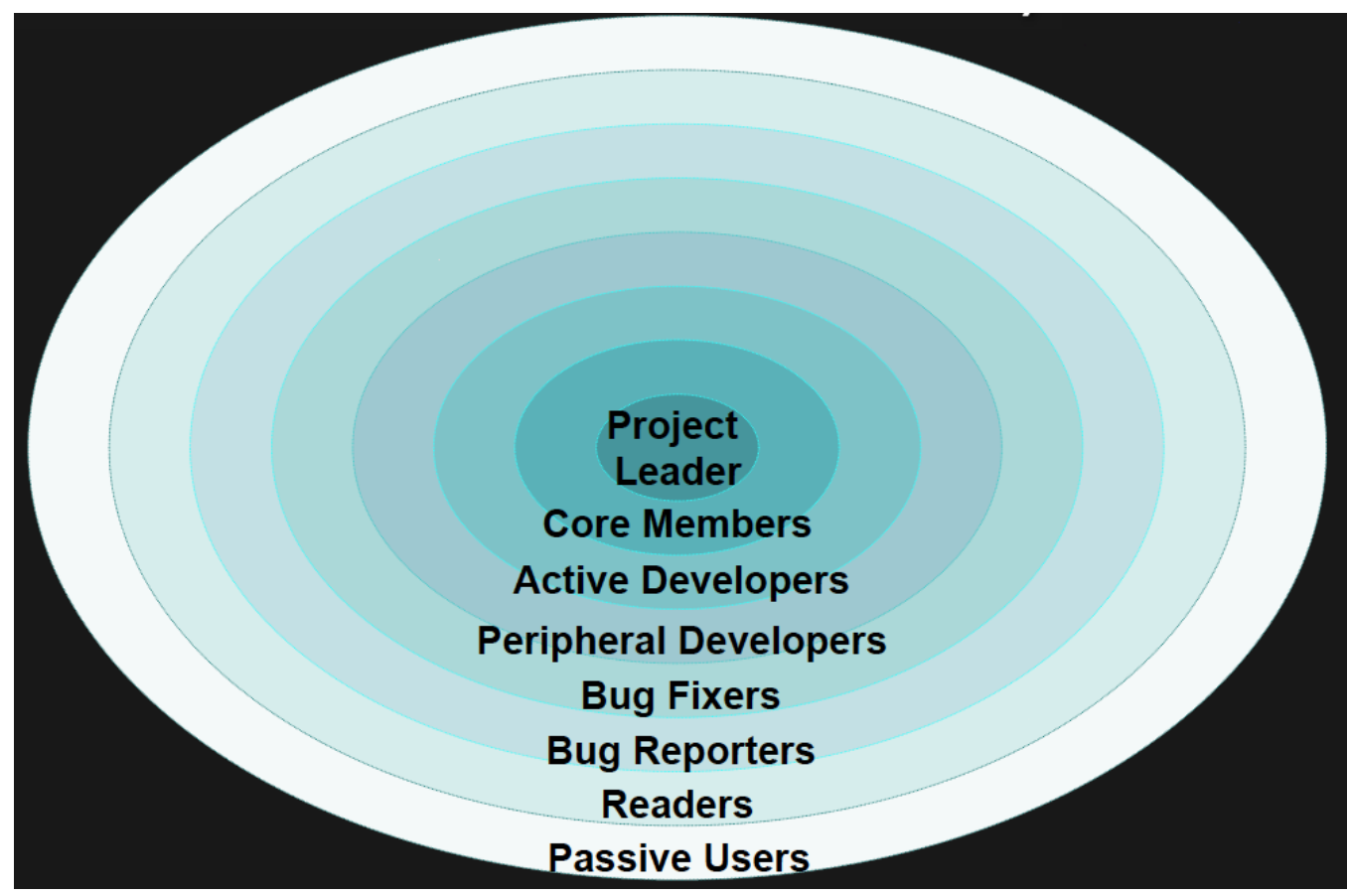

Figure 2: Ecologies of Participation in an Open Source Software Community

For cultures of participation to become viable and be successful, it is critical that a sufficient number of participants take on the more active and more demanding roles. To encourage and support migration paths towards more demanding roles, mechanisms are needed that lead to more involvement, motivation, and that facilitate the acquisition of additional knowledge required by the more demanding and involved roles. These mechanisms will include objectives such as:

- "low threshold and high ceiling" allowing new participants to contribute as early as possible, and at the same time supporting experienced participants with broad functionality for their more complex tasks;

- $\quad$ scaffolding mechanisms to support migration paths;

- special interaction mechanisms are needed for different levels of participation;

- supporting different level of granularity of participation referring to the time and effort that an individual must invest; and

- rewards and incentives needed to reduce the funnel effect [32] from one level to the next.

\section{F. Communities of Interest}

Heterogeneous "communities of interest" [33] bring together stakeholders from different homogenous "communities of practice" [34] to solve a particular (design) problem of common concern. Communities of interest have a greater creativity potential by exploiting diversity not as a constraint to deal with but an opportunity to generate new ideas, new insights, and new environments. The challenge to foster and nurture cultures of creativity is often not to reduce heterogeneity and specialization, but to support it, manage it, and integrate it by finding ways to build bridges between local knowledge and by exploiting conceptual collisions and breakdowns as sources for innovation.

The fish-scale model (see Figure 3) [2] illustrates an interesting structure for competencies that cannot be embodied in a single mind. The inevitably incomplete competence of an individual requires "Renaissance Communities" in which there is the right mixture between sufficient overlap and complementary competence. The model is structured in a way to achieve "collective comprehensiveness through overlapping patterns of unique narrowness". Each fish-scale represents a narrow specialty in depth and the overlap of one fish-scale with another provides the foundation for common ground and shared understanding between individuals being knowledgeable in different domain. Breath ("collective comprehensiveness") is achieved by collaboration. The model provides a viable path toward a new design competence based on the integration of individual and social creativity [19].

\section{SOCIO-TECHNICAL ENVIRONMENTS SUPPORTING RENAISSANCE COMMUNITIES}

The conceptual frameworks described in the previous section are grounded in a variety of different application

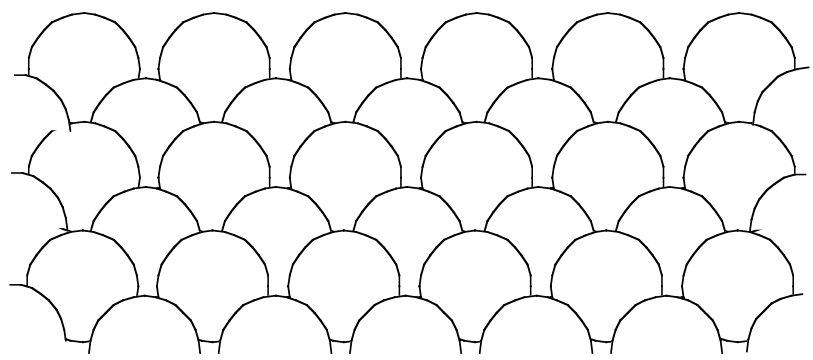

Figure 3: The Fish-Scale Model 


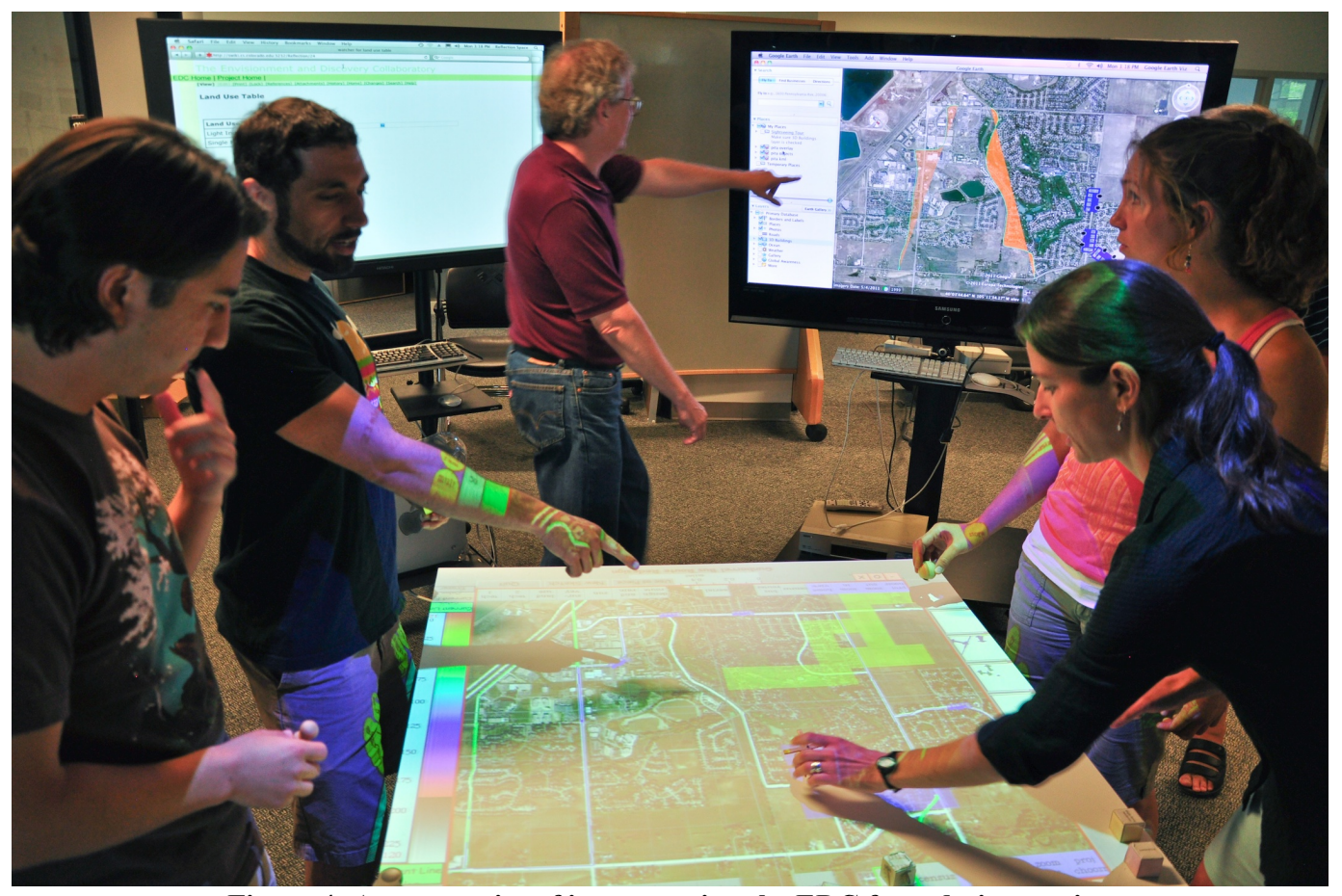

Figure 4: A community of interest using the EDC for a design session

contexts (including: urban planning, mass collaboration, and collaborative learning communities).

\section{A. The Envisionment and Discovery Collaboratory (EDC)}

The EDC [35] is a socio-technical environment in support of collaborative learning and knowledge construction. It facilitates the creation of shared understanding among various stakeholders, contextualizes information to the task at hand, and creates objects-to-think-with in collaborative design activities. It is applicable to different domains; our specific efforts have focused on the domain of urban planning and decision making.

Figure 4 shows the current realization of the EDC as a table-top computing environment. Individuals using the EDC convene around a computationally enhanced table (shown in the center of the Figure). This table serves as the action space for the EDC [36]. Realized as a touch-sensitive surface, the action space allows users to manipulate the computational simulation projected on the surface by interacting with the physical objects placed on the table. The horizontal table is flanked by a second computational whiteboard, which drives another touch-sensitive surface (shown vertically in Figure 4) serving as the EDC's reflection space. The EDC emphasizes the creation of shared interaction, common ground, and social structures between communities of learners forming a collaborative environment that builds on both distributed and face-to-face collaborations in classrooms or public sites. The EDC contributes in preparing the next generation of knowledge workers for lifelong learning and innovation in a world in which the traditional boundaries between formal educational institutions and the world at large will dissolve.

\section{B. Mass Collaboration}

Whereas in former times collaboration was mostly bound to smaller groups, the Internet tools of today provide various possibilities for the collaboration of masses of users. There is an almost unlimited variety of online communities where users share personal stories, experiences, or anything that can be expressed digitally (some representative examples are shown in Table 1). In wikis thousands of users collaboratively gather and organize knowledge. With social tagging systems users annotate and share online resources. The participants in such communities are not just a mass of learning individuals or passive consumers; they actively produce meaningful content and act as "prosumers" [37, 38].

\section{Courses-as-Seeds}

Courses-as-seeds [39] is an educational model that explores meta-design in the context of fundamentally changing the nature of courses taught in universities. Its goal is to create cultures of participation [8] that are situated in the context of university courses by supporting a community of learners model [4040]. Traditionally, the resources provided by an instructor such as lectures, readings, and assignments define the content of a course. By involving students as active contributors, courses do not have to rely only on the intellectual capital provided by an instructor. Our courses (a large number of them being available at: http:// 13d.cs.colorado.edu/ gerhard/courses/) are conceptualized based on the SER model (see Section III.B), in which the instructor provides the initial seed rather than a finished product and the content of a course evolves over time through contributions of the students. Courses-as-seeds are focused not on delivering predigested information to individuals, but providing opportunities and resources for learners to (1) engage in authentic activities, (2) participate in social debates 
Table 1: Environments Created by Cultures of Participation with Unique Features

\begin{tabular}{|c|c|}
\hline Site & Objectives and Unique Aspects \\
\hline Wikipedia & $\begin{array}{l}\text { web-based collaborative multilingual encyclopedia with a single, collaborative, and verifiable } \\
\text { article; authority is distributed (http://www.wikipedia.org/) }\end{array}$ \\
\hline KNOL & $\begin{array}{l}\text { a library of articles by recognized experts in specific domains; authors take credit and elicit peer } \\
\text { reviews; readers can provide feedback and comments; authority rests primarily with the author } \\
\text { (http://knol.google.com/) }\end{array}$ \\
\hline iTunes U & $\begin{array}{l}\text { courses by faculty members from "certified institutions"; control via input filters; material can } \\
\text { not be remixed and altered by consumers (http://www.apple.com/education/itunes-u/) }\end{array}$ \\
\hline YouTube & $\begin{array}{l}\text { video sharing website with weak input filters and extensive support for rating } \\
\text { (http://www.youtube.com/) }\end{array}$ \\
\hline $\begin{array}{l}\text { Encyclopedia of } \\
\text { Life (EoL) }\end{array}$ & $\begin{array}{l}\text { documentation of the } 1.8 \text { million known living species; development of an extensive curator } \\
\text { network; partnership between the scientific community and the general public } \\
\text { (http://www.eol.org/) }\end{array}$ \\
\hline $\begin{array}{l}\text { SketchUp and 3D } \\
\text { Warehouse }\end{array}$ & $\begin{array}{l}\text { repository of 3D models created by volunteers organized in collections by curators and used in } \\
\text { Google Earth (http://sketchup.google.com/3dwarehouse/) }\end{array}$ \\
\hline Scratch & $\begin{array}{l}\text { Learning environment for creating, remixing, and sharing programs to build creative } \\
\text { communities in education (http://scratch.mit.edu) }\end{array}$ \\
\hline Instructables & $\begin{array}{l}\text { socio-technical environment focused on user-created and shared do-it-yourself projects } \\
\text { involving others users as raters and critics (http://www.instructables.com/) }\end{array}$ \\
\hline PatientsLikeMe & $\begin{array}{l}\text { collection of real-world experiences enabling patients who suffer from life-changing diseases to } \\
\text { connect and converse (http://www.patientslikeme.com/) }\end{array}$ \\
\hline Ushahidi & $\begin{array}{l}\text { tools for democratizing information, increasing transparency and lowering the barriers for } \\
\text { individuals to share their stories; originated in the collaboration of Kenyan citizen journalists } \\
\text { during crises (http://www.ushahidi.com/) }\end{array}$ \\
\hline Stepgreen & $\begin{array}{l}\text { library of energy saving actions, tips, and recommendations by citizen contributors for saving } \\
\text { money and being environmentally responsible (http://www.stepgreen.org/) }\end{array}$ \\
\hline
\end{tabular}

and discussions, (3) create shared understanding among diverse stakeholders, and (4) frame and solve personally meaningful problems. Courses-as-seeds are grounded in sociotechnical environments in which (1) communities of mutual learners act simultaneously as learners and as active contributors (based on the assumption that being a teacher or a learner is not an attribute of a person but an attribute of a context); and (2) peer-to-peer learning is supported and teachers act as "guides on the side" rather than as "sages on the stage".

\section{IMPLICATIONS}

To foster and nurture "Renaissance Communities" requires collaborative human-centered computational systems (conceptual frameworks for and examples of such systems are briefly described in Section III and IV). Collaboration in "Renaissance Communities" is based on: (1) social distribution making activities more fun, more motivating, and by sharing the burden of coping with large problems ("getting the job done effectively and more quickly") as illustrated by the information environments created by mass collaboration; see Table 1); and (2) epistemological distribution by providing richer learning opportunities and suggesting new ways of thinking about problems (as illustrated by the EDC; see Figure 4).

Lifelong Learning. In the emerging knowledge society, lifelong learning is a necessity. Given the explosion of knowledge, people simply cannot learn in school all they will need to know in later life. Seen from this perspective, lifelong learning is more than "adult education"-it is learning carried out in the context of personally meaningful problems. In contrast to schools, where the education establishment has tried to control what people learn by defining the curriculum, self-directed learning is of critical importance in lifelong learning. To be maximally effective, however, self-directed learning needs to be supported with opportunities to explore systematic bodies of knowledge that are contextualized to the task at hand as well as to the learner's needs and interests. This design trade-off results in the dual objective of giving learners enough freedom to become active in the process of pursuing personally meaningful problems, and giving them enough guidance so that their activity results in the construction of useful knowledge and artifacts.

Massive Open Online Courses (MOOCs). One of the "hottest" topics these days is creating Higher-Ed courses with massive enrollments. There is currently a substantial hype based on developments such as: (1) MIT's and Harvard's edX project (http://www.edxonline.org/); (2) Coursera, an alliance between Stanford and a growing number of other universities (https://www.coursera.org/); and (3) Udacity, a private company (http://www.udacity.com/). Other complementary developments are: (1) the Khan Academy that advertises its role as "Watch. Practice. Learn almost anything for free with over 3,100 videos" (http://www.khanacademy.org/); (2) iTunes U (organized by Apple) supporting the design and distribution of courses to allow students to "learn anything, anywhere, any time" (http://www.apple.com/education/itunes$\mathrm{u} /$ ); and (3) the One Laptop per Child (OLPC) initiative focused on the $\$ 100$ computer, which so far has been 
delivered to over 2.4 million children and teachers primarily in developing countries (http://one.laptop.org/). are:

Interesting questions to ask based on these developments

- what is covered by MOOCs? (being free, open, and large-scale and offering learning analytics opportunities based on very large numbers of participants); and

- $\quad$ what is not covered by MOOCs? (being focused on a traditional model of an instructionist classroom, and thereby providing little support for self-directed learning, debate and discussions, and reflective conversations).

MOOCs enrich the landscape of learning opportunities and they have the potential to reduce the digital divide by providing education for everyone. They also challenge residential, research-based universities to reflect, define, and emphasize their core competencies: moving away from large lectures with learners listening to teachers towards active learning environments characterized by personal attention from teachers and opportunities for participation, and thereby looking beyond the simplicities of information to the complexities of learning.

\section{CONCLUSIONS}

In the past, most computational environments have focused on the needs of individual users. Our research has evolved from empowering Renaissance Scholars in specific domains (e.g., with domain-oriented design environments) to creating shared understanding among "Renaissance Communities" as communities of interest.

The world has become too complex for individuals (even when they are educated and act as Renaissance Scholars) to have enough knowledge to tackle complex problems by themselves. The necessary and viable alternative is to support, foster, nurture and sustain "Renaissance Communities". Bringing people with different background knowledge and different value systems together, overcoming the biases and barriers of their separate languages, integrating different educational experiences, and eliminating the lack of reward structures will not be an easy undertaking. But there is little choice: unless we meet these challenges, we will be unable to cope with the complexities and needs posed by the problems of the 21 st century.

\section{ACKNOWLEDGMENTS}

The ideas, concepts, arguments, and system developments described in this papers have been jointly developed over the last two decades with former and current members of the Center for Lifelong Learning \& Design (L3D) at CU Boulder (http://13d.cs.colorado.edu).

The research was supported in part by the following grants from the National Science Foundation: (1) REC-0106976 "Social Creativity and Meta-Design in Lifelong Learning Communities"; (2) IIS-0613638 "A Meta-Design Framework for Participative Software Systems"; (3) IIS-0709304 "A New Generation Wiki for Supporting a Research Community in Creativity and IT"; (4) OCI-1028017 "CDI-Type I:
Transformative Models of Learning and Discovery in Cultures of Participation"; and (5) IIS-1111025 "SoCS: Theoretical Frameworks and Socio-Technical Systems for Fostering Smart Communities in Smart Grid Environments".

Some arguments of the article were developed under support of a "Chair of Excellence" fellowship granted to the author by the University Carlos III of Madrid.

\section{REFERENCES}

[1] B. Shneiderman, Leonardo's Laptop - Human Needs and the New Computing Technologies. Cambridge, Mass: MIT Press, 2002.

[2] D. T. Campbell, "Ethnocentrism of Disciplines and the Fish-Scale Model of Omniscience," in Interdisciplinary Collaboration - An Emerging Cognitive Science, S. J. Derry, C. D. Schunn, and M. A. Gernsbacher, Eds., ed Mahwah, NJ: Lawrence Erlbaum, 2005, pp. 3-21.

[3] V. John-Steiner, Creative Collaboration. Oxford: Oxford University Press, 2000.

[4] M. Csikszentmihalyi, Creativity - Flow and the Psychology of Discovery and Invention. New York, NY: HarperCollins Publishers, 1996.

[5] W. Bennis and P. W. Biederman, Organizing Genius: The Secrets of Creative Collaboration. Cambridge, MA: Perseus Books, 1997. E. S. Raymond and B. Young, The Cathedral and the Bazaar: Musings on Linux and Open Source by an Accidental Revolutionary. Sebastopol, CA: O'Reilly \& Associates, 2001.

[7] G. Fischer and M. Sugimoto, "Supporting Self-Directed Learners and Learning Communities with Sociotechnical Environments," International Journal Research and Practice in Technology Enhanced Learning (RPTEL), vol. 1, pp. 31-64, 2006.

[8] G. Fischer, "Understanding, Fostering, and Supporting Cultures of Participation," ACM Interactions vol. XVIII.3 (May + June 2011), pp. 42-53, 2011.

[9] G. Fischer and J. Ostwald, "Knowledge Communication In Design Communities," in Barriers and Biases in Computer-Mediated Knowledge Communication, R. Bromme, F. W. Hesse, and H. Spada, Eds., ed New York, N.Y.: Springer, 2005, pp. 213-242.

[10] J. Bruner, The Culture of Education. Cambridge, MA: Harvard University Press, 1996.

[11] I. Illich, Deschooling Society. New York: Harper and Row, 1971.

[12] National-Research-Council, Learning Science in Informal Environments - People, Places, and Pursuits. Washington, DC: National Academy Press, 2009.

[13] G. Fischer, "Context-Aware Systems: The 'Right' Information, at the 'Right' Time, in the 'Right' Place, in the 'Right' Way, to the 'Right' Person," in Proceedings of the Conference on Advanced Visual Interfaces (AVI 2012), G. Tortora, S. Levialdi, and M. Tucci, Eds., ed Capri, Italy (May): ACM, 2012, pp. 287-294.

[14] G. Fischer, "Supporting Learning on Demand with Design Environments," in International Conference on the Learning Sciences (Evanston, IL), L. Birnbaum, Ed., ed: Association for the Advancement of Computing in Education, 1991, pp. 165-172.

[15] A. Collins and R. Halverson, Rethinking Education in the Age of Technology: The Digital Revolution and the School. New York, NY: Teachers College Press 2009.

[16] E. von Hippel, Democratizing Innovation. Cambridge, MA: MIT Press, 2005.

[17] Y. Benkler, The Wealth of Networks: How Social Production Transforms Markets and Freedom. New Haven, CT: Yale University Press, 2006.

[18] J. S. Brown. (2005). New Learning Environments for the 21st Century. Available:

http://www.johnseelybrown.com/newlearning.pdf

[19] G. Fischer, E. Giaccardi, H. Eden, M. Sugimoto, and Y. Ye, "Beyond Binary Choices: Integrating Individual and Social Creativity," International Journal of Human-Computer Studies (IJHCS) Special Issue on Computer Support for Creativity (E.A. Edmonds \& L. Candy, Eds.), vol. 63, pp. 482-512, 2005.

[20] A. Gorman and G. Fischer, "Toward an Analytic Framework for Understanding and Fostering Peer-Support Communities in Using 
and Evolving Software Products," in Proceedings of the International Conference Communities and Technologies (C\&T'2009) Penn State University, June ed, 2009, pp. 1-9.

[21] A. Collins, G. Fischer, B. Barron, C. Liu, and H. Spada, "LongTail Learning: A Unique Opportunity for CSCL?," in Proceedings (Vol 2) of CSCL 2009: 8th International Conference on Computer Supported Collaborative Learning, University of the Aegean, Rhodes, Greece, ed, 2009, pp. 22-24.

[22] J. S. Brown and R. P. Adler. (2008). Minds on Fire: Open Education, the Long Tail, and Learning 2.0. Available: http://www.educause.edu/ir/library/pdf/ ERM0811.pdf

[23] G. Fischer. (2002). Beyond 'Couch Potatoes': From Consumers to Designers and Active Contributors, in FirstMonday (PeerReviewed Journal on the Internet). Available: http://firstmonday.org/htbin/cgiwrap/bin/ojs/index.php/fm/article/v iew/1010/931

[24] L. B. Resnick, "Learning in School and out," Educational Researcher, vol. 16, pp. 13-20, 1987.

[25] G. Fischer and E. Giaccardi, "Meta-Design: A Framework for the Future of End User Development," in End User Development, $\mathrm{H}$. Lieberman, F. Paternò, and V. Wulf, Eds., ed Dordrecht, The Netherlands: Kluwer Academic Publishers, 2006, pp. 427-457.

[26] J. Bransford, N. Vye, R. Stevens, P. Kuhn, D. Schwartz, P. Bell, A Meltzoff, B. Barron, R. Pea, B. Reeves, J. Roschelle, and N. Sabelli, "Learning Theories and Education: Toward a Decade of Synergy," in Handbook of Educational Psychology (2nd ed), P. Alexander and P. Winne, Eds., ed Mahwah, NJ: Erlbaum, 2006, pp. 209-244.

[27] H. Rittel, "Second-Generation Design Methods," in Developments in Design Methodology, N. Cross, Ed., ed New York: John Wiley \& Sons, 1984, pp. 317-327.

[28] S. Turkle and S. Papert, "Epistemological Pluralism and the Revaluation of the Concrete," in Constructionism, I. Harel and S. Papert, Eds., ed Norwood, NJ: Ablex Publishing Corporation, 1991, pp. 161-191.

[29] I. Janis, Victims of Groupthink. Boston: Houghton Mifflin, 1972.

[30] J. Preece and B. Shneiderman, "The Reader-to-Leader Framework: Motivating Technology-Mediated Social Participation," AIS Transactions on Human-Computer Interaction, vol. 1, pp. 13-32, 2009.
[31] Y. Ye and G. Fischer, "Designing for Participation in SocioTechnical Software Systems," in Proceedings of 4th International Conference on Universal Access in Human-Computer Interaction (Part I) C. Stephanidis, Ed., ed Heidelberg: Springer, 2007, pp. 312-321.

[32] J. Porter, Designing for the Social Web. Berkeley, CA: New Riders., 2008.

[33] G. Fischer, "Communities of Interest: Learning through the Interaction of Multiple Knowledge Systems," in 24th Annual Information Systems Research Seminar In Scandinavia (IRIS'24), Ulvik, Norway, 2001, pp. 1-14.

[34] E. Wenger, Communities of Practice - Learning, Meaning, and Identity. Cambridge, UK: Cambridge University Press, 1998.

[35] E. G. Arias, H. Eden, G. Fischer, A. Gorman, and E. Scharff, "Transcending the Individual Human Mind-Creating Shared Understanding through Collaborative Design," in HumanComputer Interaction in the New Millennium, J. M. Carroll, Ed., ed New York: ACM Press, 2001, pp. 347-372.

[36] D. A. Schön, The Reflective Practitioner: How Professionals Think in Action. New York: Basic Books, 1983.

[37] T. O'Reilly. (2005). What Is Web 2.0 - Design Patterns and Business Models for the Next Generation of Software. Available: http://www.oreillynet.com/pub/a/oreilly/tim/news/2005/09/30/what -is-web-20.html

[38] D. Tapscott and A. D. Williams, Wikinomics: How Mass Collaboration Changes Everything. New York: Portofolio, Penguin Group, 2006.

[39] R. dePaula, G. Fischer, and J. Ostwald, "Courses as Seeds: Expectations and Realities," in Proceedings of The European Conference on Computer-Supported Collaborative Learning, P. Dillenbourg, A. Eurelings, and K. Hakkarainen, Eds., ed Maastricht, Netherlands, 2001, pp. 494-501.

[40] B. Rogoff, E. Matsuov, and C. White, "Models of Teaching and Learning: Participation in a Community of Learners," in The Handbook of Education and Human Development - New Models of Learning, Teaching and Schooling, D. R. Olsen and N. Torrance, Eds., ed Oxford: Blackwell, 1998, pp. 388-414. 